\title{
Spur Gear Designing and Weight Optimization
}

\author{
Mr. Naveen Kumar'1, Mr. Vaibhav Chittoria², Mr. Utkarsh Upadhyay² \\ ${ }^{1}$ Assistant Professor, ${ }^{2}$ Student, \\ Department of Mechanical Engineering, ABES Engineering College, \\ Ghaziabad, U.P., India.
}

Abstract :- In this paper, we are designing and optimizing of gear for event SAE BAJA Transmission. The given values of forces, torque and factor of safety of gear are calculated in accordance to custom vehicle. The gear is designed using SOLIDWORKS Toolbox. Gear weight is optimized by material removal from specific region. After it, simulation on SOLIDWORKS and ANSYS is done giving input values from calculation. The result shows the difference in weight and factor of safety between optimized and un-optimized gear models.

\section{INTRODUCTION :-}

Gear is used gain mechanical advantage in power transmission. Gears of different types: Spur Gear, Helical Gear, Bevel Gear, Worm and Wheel Gear. Gears are commonly used in Transmission of Automobiles via Gearbox. Transmission assembly are stated: Simple Gear train, Compound Gear train, Planetary, etc. Weight of gears in gearbox becomes a constant factor of vehicle weight as whole. In college projects like SAE BAJA, SUPERA, etc. the basic knowledge of transmission is seen by an engineer skill to design a gearbox of required strength and maintain lightweight. The vehicle this gear is designed for uses a Engine power source with CVT.

- To choose material of high strength.

\section{OBJECTIVE:-}

- To calculate the theoretical forces on spur gear by conventional formulas.

- To model the spur gears on SOLIDWORKS using toolbox spur gear.

- To remove material and optimize weight of spur gear.

- To simulate gear on SOLIDWORKS and ANSYS.

\section{THEORETICAL ANALYSIS}

ANALYSIS:-

Gear Material

Material for Gear is chosen based on yield strength of material. Materials commonly used are AISI 4340, EN 353, etc. We have taken AISI 4340 for its high strength. The properties are as in Table 1.

Table 1

AISI 4340 Properties

\begin{tabular}{|c|c|}
\hline \multicolumn{2}{|c|}{} \\
\hline Density & $7.8 \mathrm{gm} / \mathrm{cm} 3$ \\
\hline Hardness(BH) & 320 \\
\hline Young's modulus & $200 \mathrm{GPa}$ \\
\hline Poisson's ratio & 0.30 \\
\hline Yield strength & $710 \mathrm{MPa}$ \\
\hline Ultimate tensile strength & $1110 \mathrm{MPa}$ \\
\hline
\end{tabular}

Engine

Engine used here is Briggs and Stratton engine, Model 19(Fig. 1). Its specifications are given in Table 2.

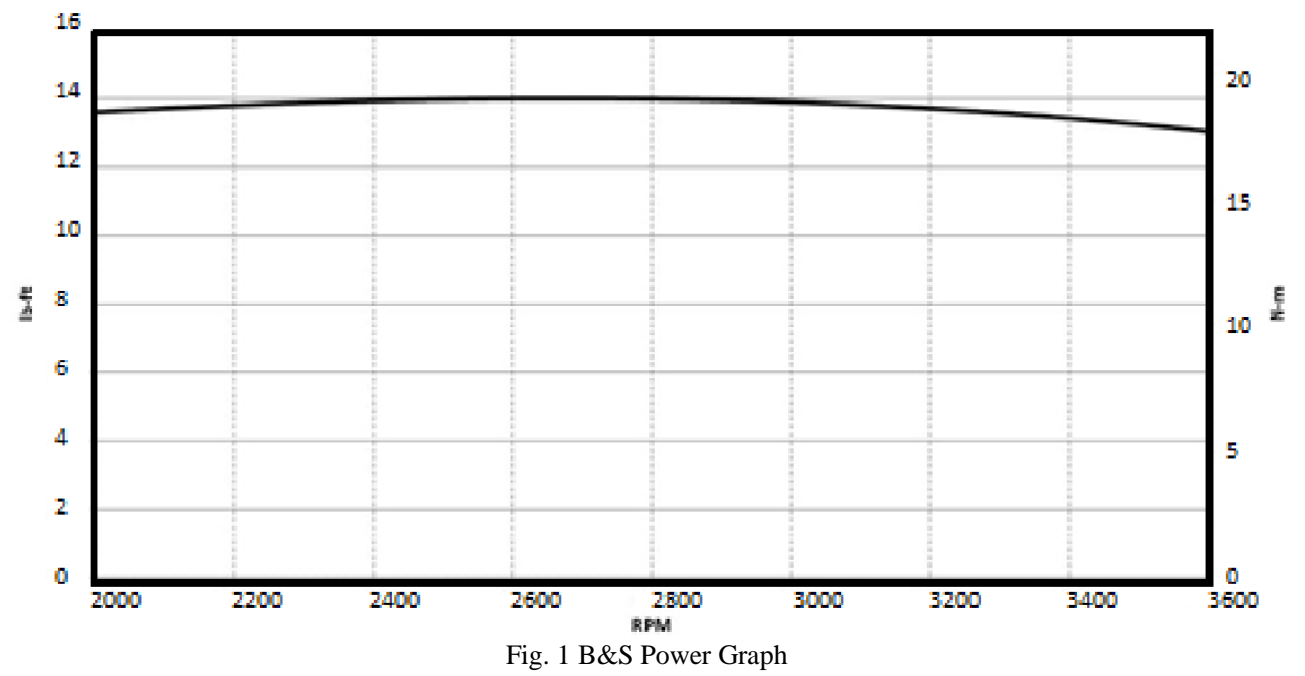


Table 2

Input Engine

\begin{tabular}{|c|c|}
\hline Model & 19L232-0054 G1 \\
\hline Compression ratio & 8.1 to 1 \\
\hline Bore/Stroke & 3.12 " 2.44 " \\
\hline HP(Gross) & $10.0 \mathrm{Hp}$ \\
\hline Max. RPM & $3800 \mathrm{rpm}$ \\
\hline Max. Torque & $19.6 \mathrm{Nm}$ at 2800 rpm \\
\hline
\end{tabular}

Continuous Variable Transmission (CVT) is used as constant reduction between engine output and gearbox input. Specifications are given in Table 3 .

Table 3

CVT Specifications

\begin{tabular}{|c|c|}
\hline CVT & Polaris \\
\hline Max. ratio & $3: 1$ \\
\hline Min. ratio & $0.7: 1$ \\
\hline
\end{tabular}

\section{Calculation}

\section{Torque on gear}

Torque is transferred from engine to gearbox after reduction from CVT. The final torque on gear is:-

$\mathrm{M}_{\mathrm{t}}$ - torque input at gear

$\mathrm{M}_{\mathrm{t}}=\max$. torque of engine $* \max . \mathrm{CVT}$ ratio $*$ Gear reduction ratio

$\mathrm{M}_{\mathrm{t}}=19.6 * 3 * 7.54$

$\mathrm{M}_{\mathrm{t}}=443 \approx 450 \mathrm{Nm}$

\section{Spur Gear nomenclature}

Basic dimensions of Gear are given:-

$\operatorname{Module}(\mathrm{m})=2.5$

Number of $\operatorname{Teeth}(\mathrm{z})=59$

Pitch Circle Diameter $(\mathrm{d})=\mathrm{m}^{*} \mathrm{z}=147.5 \mathrm{~mm}$

Width of Gear(b) $=20 \mathrm{~mm}$

Output Shaft Diameter $=36 \mathrm{~mm}$

\section{Calculation of Tangential Force}

The two components of net force on gear tooth are: Radial force $\left(\mathrm{F}_{\mathrm{r}}\right)$, Tangential force $\left(\mathrm{F}_{\mathrm{t}}\right)$. The only force responsible of gear rotation is $F_{t}$, calculated below:-

$\mathrm{F}_{\mathrm{t}}$ - Tangential force applied on gear tooth/teeth

$\mathrm{Ft}=2 * \mathrm{Mt} / \mathrm{d}$

$\mathrm{Ft}=2 * 450 * 1000 / 147.5$

$\mathrm{Ft}=6101.6949 \mathrm{~N}$

\section{Calculation of Beam Strength of Gear Teeth}

The resistive force offered by gear tooth is calculated below:-

$\mathrm{F}_{\mathrm{en}}$ - Resistive force of Gear tooth

$\sigma_{\mathrm{en}}-$ Allowable permissible stress of material

$\sigma_{\mathrm{ut}}-$ Ultimate tensile stress of material

$\sigma_{\mathrm{en}}=\sigma_{\mathrm{ut}} / 3$

$\mathrm{F}_{\mathrm{en}}=\sigma_{\mathrm{en}} * \mathrm{~b} * \mathrm{Y} * \mathrm{~m}$

$\mathrm{F}_{\mathrm{en}}=(1110 / 3) * 20 *[\pi *(0.175-0.95 / 59)] * 2.5$

$\mathrm{F}_{\mathrm{en}}=9235.0843 \mathrm{~N}$

\section{Calculated Factor of Safety(FOS)}

Factor of Safety is calculated:-

$\mathrm{FOS}=\mathrm{F}_{\mathrm{en}} / \mathrm{F}_{\mathrm{t}}$

FOS $=9235.0843 / 6101.6949$

$\mathrm{FOS}=1.51$

\section{GEAR DESIGNING}

For Gear model, we take a standard spur gear from SOLIDWORKS Toolbox. Assign the Module and Teeth number. The software will generate a gear using Global Equations. We optimize it according to design using Static Simulation.

For simulation the center hub is fixed fixture and tangential force is applied on teeth for worst condition possible.

Simulation of Gear on SOLIDWORKS Fig. 2, 3. 
Model name:gear2 3.1

Study name:Static 4(-Default-)

Plot type: Static nodal stress Stress 1

Deformation scale: 1

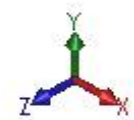

\section{-Isometric}

Model name:gear2 3.1

Study name:Static 4 (-Default-)

Plot type: Factor of Safety Factor of Safety 1

Criterion : Maxvon Mises Stress

Factor of safety distribution: Min FOS $=2.3$
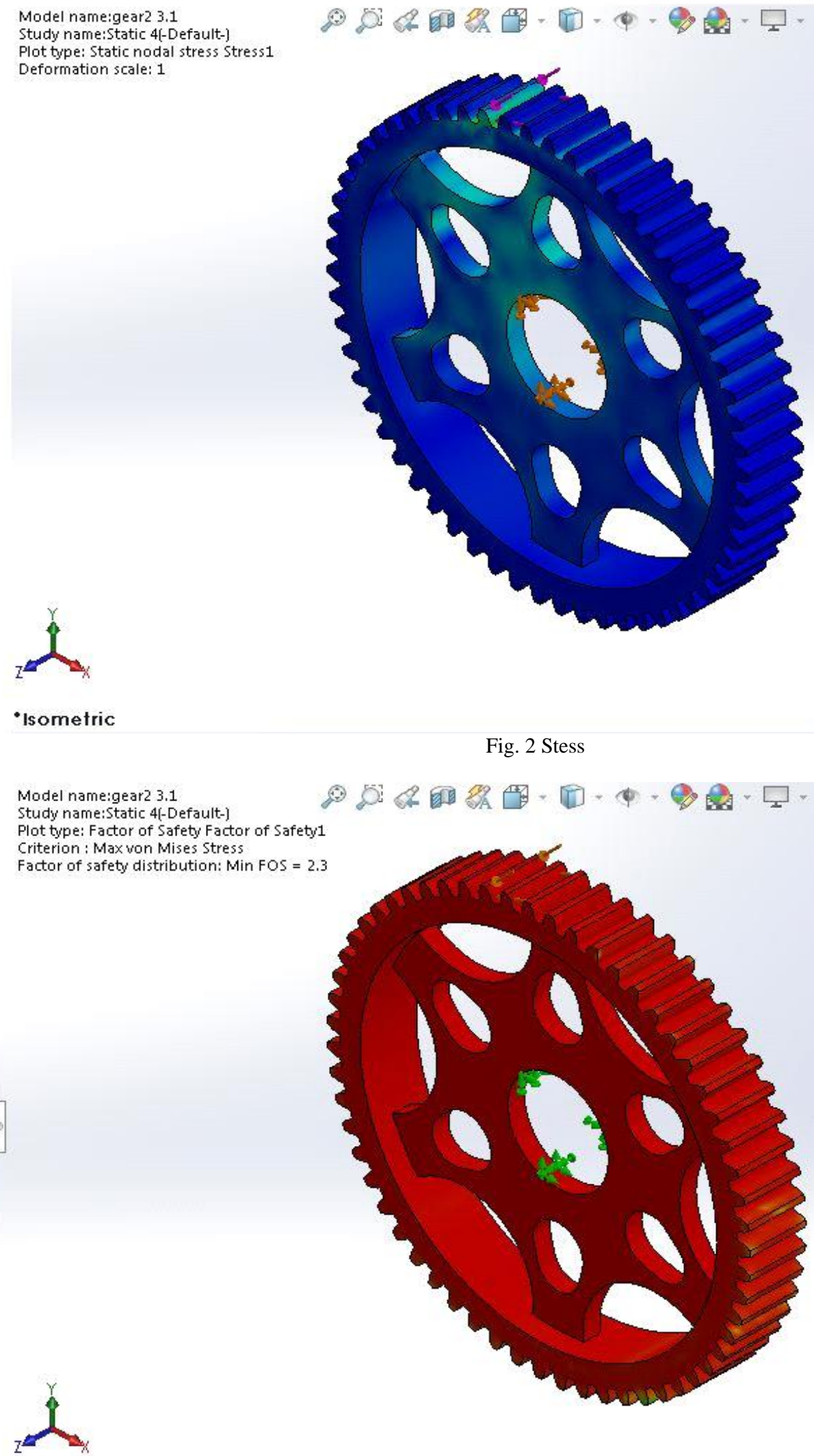

von Mises $\left(\mathrm{N} / \mathrm{m}^{\wedge} 2\right)$

$3.098 \mathrm{e}+08$

$2.840 e+08$

$2.582 \mathrm{e}+08$

$2.323 e+08$

$2.065 e+08$

$1.807 e+08$

$1.549 \mathrm{e}+08$

$1.291 \mathrm{e}+08$

$1.033 \mathrm{e}+08$

$7.746 \mathrm{e}+07$

$5.165 \mathrm{e}+07$

$2.584 \mathrm{e}+07$

$2.281 e+04$

$\rightarrow$ Yield strength: $7.100 \mathrm{e}+08$

Fig. 2 Stess
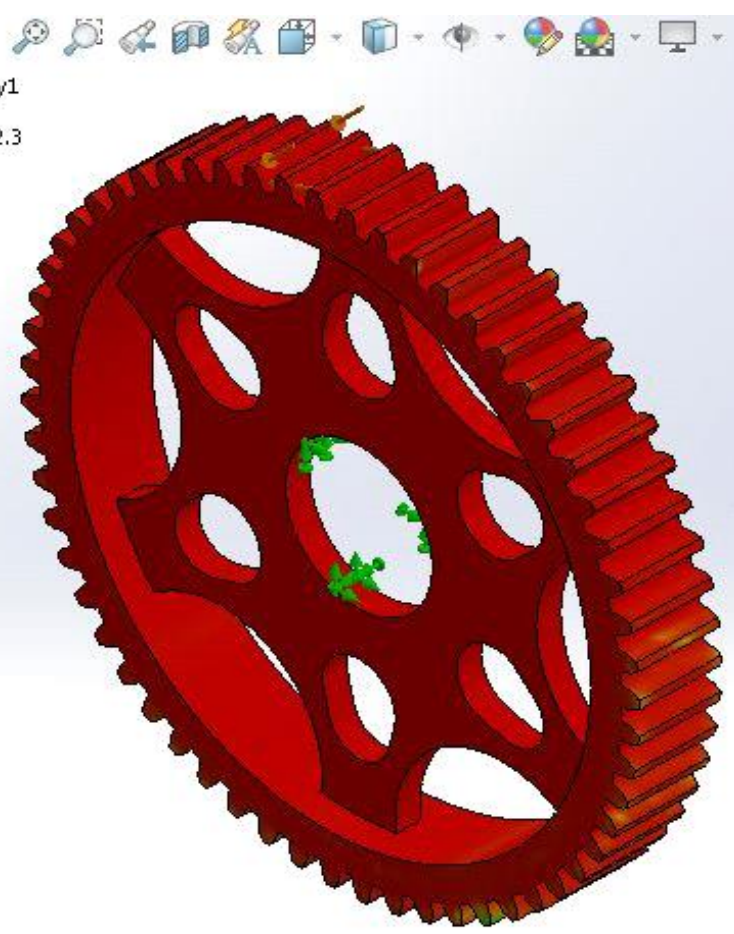

FOS

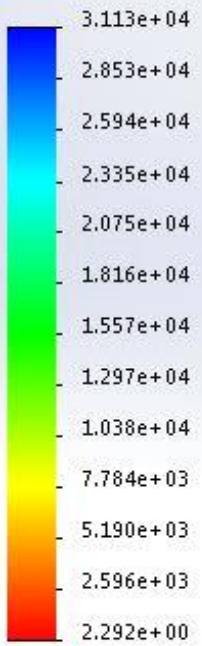

Fig. 3 Factor of Safety 
Simulation of Gear on ANSYS Fig. 4, 5.
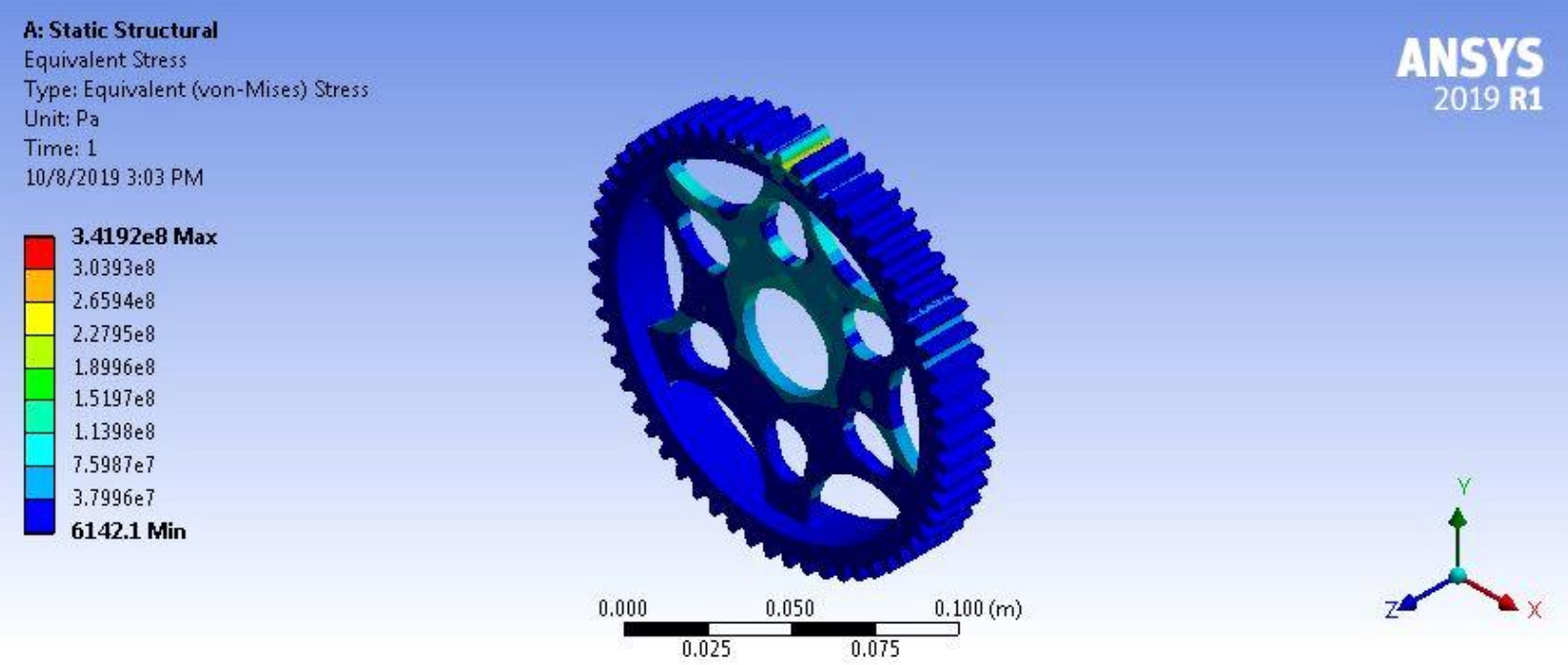

Fig. 4 Stress
A: Static Structural
Safety Factor
Type: Safety Factor
Time: 1
10/8/2019 3:02 PM

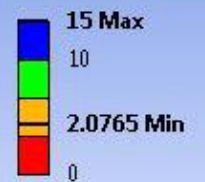

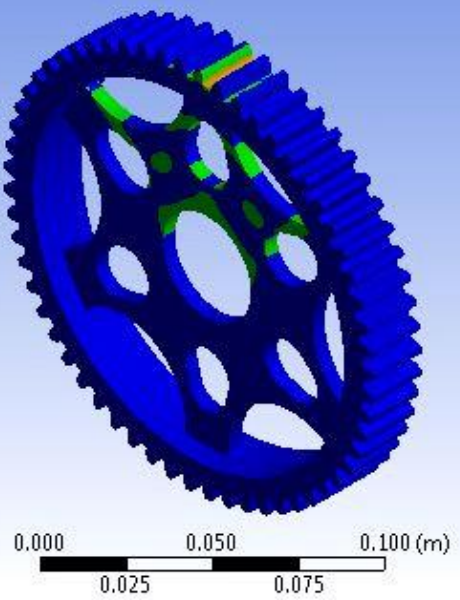

ANSYS

2019 R1

Fig. 5 Factor of Safety

\section{RESULT :-}

After simulations, we got the following results give in Table 4.

Table 4

Comparison Result

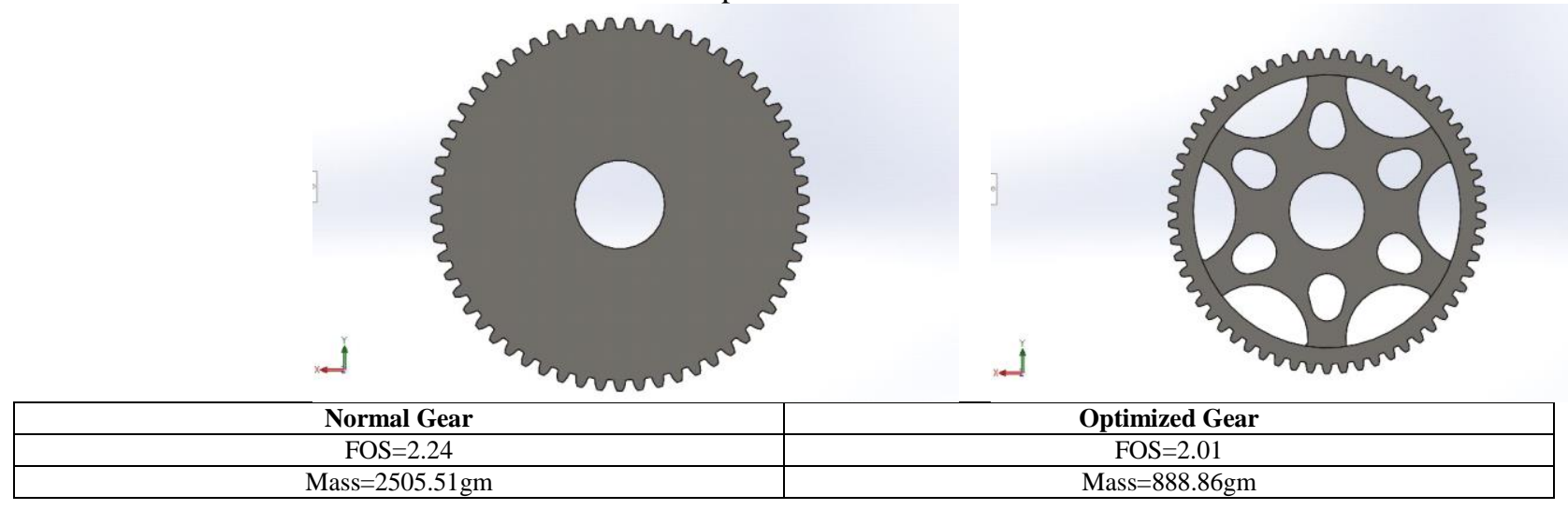




\section{REFRENCE}

[1] K. Mahadevan, K. Balaveera Reddy; Design Data Handbook, Fourth Edition(2019)

[2] V. N. Bhandari; Design of Machine Elements, Third Edition.

[3] Raja. S, Ramaswamy. K and Lokesh. M; WEIGHT OPTIMIZATION OF HELICAL GEAR UNDER STATIC ANALYSIS, International Journal of Mechanical Engineering and Technology (Volume 9, Issue 9, September 2018).

[4] Chinmay Shah, Swapnil Thigale, Rathin Shah; OPTIMIZATION WEIGHT OF A GEAR USING TOPOLOGY OPTIMIZATION, International Journal of Science, Engineering and Technology Research (Volume 7, Issue 6, June 2018).

[5] Mr. Dattatray A. Patil, Prof. Dalwe D.M.; DESIGN AND WEIGHT OPTIMIZATION OF PINION BY USING FEA METHOD, International Research Journal of Engineering and Technology (Volume 4, Issue 6, June -2017).

[6] Mahesh. Badhite, Srimanthula Srikanth, Jithendra Bodapali; STRESS REDUCTION AND ANALYSIS OF A SPUR GEAR TOOTH, International Journal of Emerging Technology and Advanced Engineering (Volume 4, Issue 3, March 2014).

[7] Amit Patil, BENDING STRESS ANALYSIS OF SPUR GEAR, International Journal for Research in Applied Science \& Engineering Technology (Volume 5, Issue 6, June 2017) 